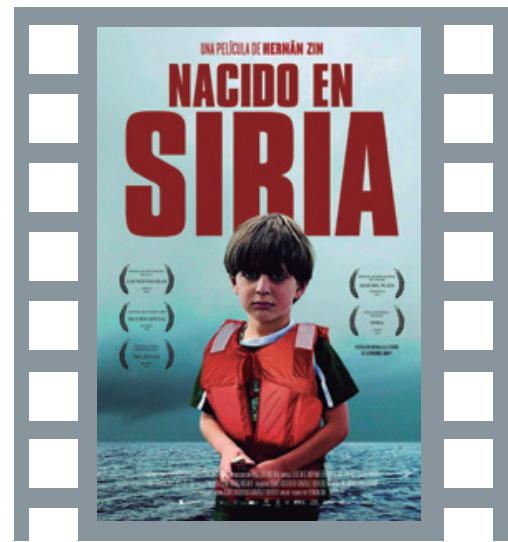

\section{Ficha têcnica}

Título original: Nacido en Siria

Nacionalidad: España y Dinamarca

Dirección: Hernán Zin

Guión: Jose F. Ortuño, Hernán Zin

Productora: Contramedia Films; La Claqueta P.C.; Final Cut For Real

Colaboración: Java Films

Año: 2016

Música: Gabriel Yared y Jean Pierre Ensuque

Fotografía: Hernán Zin Gabriel Yared y Jean Pierre Ensuque

Género: Documental

Duración: 86 minutos

Premios: 2017 - Nominación al Premio Goya al Mejor Documental. 2017 -

Premio José María Forqué al Mejor Documental. 2017 - Premio Platino a la

Mejor Película Documental.

\title{
Nacido en Siria
}

Los diferentes, los desplazados y los refugiados son los que enriquecen todas nuestras vidas; su tolerancia e imparcialidad hacia ellos abrirá nuevos mundos para ustedes y los hará bienvenidos

donde sea que vayan.

Kofi Annan

Concha Fernández-Soto, Francisco Majuelos Martínez

y Carmen Pereira Domínguez

conchafdezsoto@gmail.com,pacomajuelos@telefonica.net y

mcdguez@uvigo.es

\section{La historia}

Debido a la guerra civil en Siria, en 2011, más de cuatro millones de sirios han dejado el país huyendo de la violencia. Más de la mitad de ellos son niños. Este hecho significa el mayor éxodo de refugiados del siglo XXI.

Se refleja el drama de los refugiados, en especial, desde el prisma de la infancia indefensa. A través de siete historias de guerra, dolorosas y desesperantes, vividas en silencio, valentía, esperanza y superación, entenderemos el sentido de haber nacido en Siria.

Entre septiembre de 2015 y julio de 2016, se narra el viaje de estos niños desde que dejaron su país destruido por la guerra. Han atravesado el mar en patera hasta llegar a Turquía y luego a Serbia, Hungría, Croacia, Eslovenia, Alemania y Bélgica. Una larga y cruda vivencia en campos de refugiados, en busca de un nuevo futuro. El documental nos lleva a la reflexión para mejorar este conflicto humano.

\section{Temas}

Campos de refugiados

Derechos Humanos

Educación familiar

Infancia y guerra

Inmigración

Muerte

Mujer

Organizaciones no gubernamentales

Prejuicios sociales

Trabajo

\section{Valores}

Compromiso
Convivencia pacífica
Emociones
Esperanza
Interculturalidad
Respeto
Responsabilidad
Solidaridad
Tolerancia
Vida digna

\section{(r.) Antes de ver la película}

1. Ubicamos Siria en Google Maps, en relación a los países de la Unión Europea y del mar Mediterráneo. ¿Cómo viajarías desde Siria a Alemania 0 a Bélgica?

2. Localizamos en el mapa las ciudades de Alepo, Konya, Behram, Lesbos, Atenas, Idomeni, Belgrado, Röske, Budapest, Aachen, Bruselas y Berlín. Calculamos las distancias del trayecto. ¿Cuántos países atravesamos?

3. Buscamos en Internet sobre las civilizaciones desarrolladas en el territorio que actualmente ocupa Siria, y sobre su historia reciente. También, sobre la guerra actual: ¿quiénes son los bandos contendientes?, ¿qué motivos esgrimen cada uno de ellos?, ¿quiénes y por qué los apoyan?

4. Sitúa geográficamente a los kurdos e indaga sobre su papel en el conflicto.

5. ¿Quiénes son los refugiados?, ¿qué organismos se ocupan de ellos?, ¿dónde están?, ¿quién los cobija en Europa?, ¿cuántos acogeremos en España?

6. Estudiamos la Declaración Unión Europea-Turquía, del 18 de marzo de 2016. ¿Cuál es su finalidad y qué efectos ha tenido sobre los refugiados?

7. Averiguamos sobre la ONG Open Arms y sus actividades. ¿Qué iniciativas sociales en solidaridad con los refugiados conocéis en España?
8. ¿Qué situaciones han provocado éxodo de refugiados españoles en algún momento de nuestra historia? Haz una relación de ellos y busca las causas que causaron su huida y los itinerarios que recorrieron.

9. Para saber más: CIDOB (2014) Una guía al conflicto sirio: 10 preguntas claves https://www.cidob.org/publicaciones/documentacion/dossiers/conflicto_en_siria/dossier_conflicto_en_siria La Unión Europea y la Crisis de los Refugiados http://publications. europa.eu/webpub/com/factsheets/refugee-crisis/es/ Declaración UE-Turquía, 18 de marzo de 2016 http://www.consilium.europa.eu/es/press/pressreleases/2016/03/18-eu-turkey-statement/

Cuaderno de trabajo de la APDHA: La crisis de la llegada de personas que piden refugio a Europa

https://apdha.org/cadiz/wp-content/uploads/Cuadernillo-de-formación-y-debate.pdf

La UE pierde su alma ante los refugiados

http://lucasfra.blogs.uv.es/2016/07/07/la-ue-pierde-su-almaante-los-refugiados/

Conferencia, "Refugiados e Inmigrantes". Javier de Lucas. https://www.youtube.com/watch?v=b6s6WF6wTDE 


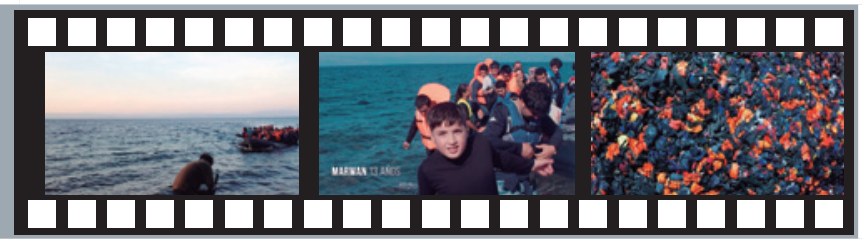

1.1. En el mar. La película comienza con imágenes del rescate hasta la costa de un grupo de refugiados, auxiliados por miembros de una ONG. Muestra la desorientación nada más pisar tierra (00:03:18).

1.2. Isla de Lesbos. Marwan, un chiquillo que viaja con su familia relata, al llegar a Lesbos, sus miedos sobre el viaje y los recuerdos de la guerra, sus preocupaciones y las de su familia (00:07:15).

1.3. Campo de refugiados de Oxi. Buscan un lugar para pasar la noche. Llegan al campo de refugiados de Oxi donde no hay sitio para ellos (00:08:06).

1.4. Septiembre 2015. Frontera entre Serbia y Hungría. Una familia intenta cruzarla y un miembro queda atrás (00:09:45).

1.5. El discurso de Viktor Orbán, conminando a los refugiados a que se queden en Turquía (00:10:25).

1.6. Rozke, Hungría. Arasuli cuenta sus vivencias de la guerra, las vicisitudes del viaje y el trato recibido de la policía húngara, mientras esperan pasar al campo de refugiados (00:13:09).

1.7. Lesbos, Grecia. Marwan entra con su familia al campo de refugiados de Lesbos, desde allí los trasladarán al continente (00:15:20).

1.8. Budapest. Gassem viaja con la familia de sus tíos y narra la situación de los refugiados hacinados en la estación de tren de Budapest. También sus recuerdos de la guerra y sus experiencias en Budapest (00:19:30).

1.9. De Budapest a Viena. La expulsión de refugiados de Hungría y su traslado a Austria, a través de las informaciones de la prensa (00:21:22).

1.10. Campo de refugiados de Nickelsdorf. Hamude recorre el campo con su patín, como ajeno a los acontecimientos. Viaja con su tío (00:25:05).

1.11. Octubre 2015. Frontera serbo-croata. Marwan describe la travesía por territorio serbio y croata hasta llegar a Eslovenia (00:29:18).

1.12. Noviembre 2015. Eslovenia. Las imágenes del éxodo se acompañan del discurso de la invasión (00:29:55).

1.13. Frontera entre Eslovenia y Austria. Jiham, chica de 13 años, viaja con su padre. Relata el paso incierto de la frontera entre Eslovenia y Austria; sus recuerdos de la guerra y su vida en Líbano, donde dejó a su madre y hermanos (00:35:00).

1.14. Diciembre 2015. Campo de Refugiados de Hotton, Bélgica. Alegría de Marwan y su familia por la concesión de una casa. Aún le brotan recuerdos del viaje. Reciben noticias de sus allegados en Siria, donde la guerra sigue (00:38:20)

1.1. ¿Cómo son las condiciones del viaje y las dificultades del rescate? ¿Pensáis que la técnica de grabación cámara en mano aporta dramatismo a la historia?

1.2. ¿Qué os sugieren las imágenes de restos de objetos abandonados en la playa? ¿Y la frase de Marwan "al principio pensaba que el problema sólo era cruzar el mar. Pero ahora que hemos llegado no hay nadie que nos diga dónde ir"?

1.3. Comentamos sobre el abandono y desamparo en que se encuentra la familia.

1.4. ¿Qué riesgos corren los refugiados al pasar las fronteras alambradas?

1.5. Relacionamos este discurso con las imágenes que le acompañan.

1.6. ¿Qué opinión os merecen las mafias a las que se refiere Arasuli y el precio que les cobran por trasladarlos?

1.7. ¿Cómo afronta Marwan esta etapa de su periplo?

1.8. Se producen conflictos entre refugiados, ite imaginas los motivos y las causas?, ¿cómo interpretamos la negativa de hoteles y taxis a aceptarlos aun pudiendo pagar los servicios?, ¿cómo se siente Gassem?

1.9. ¿Fueron acertadas las medidas del gobierno de Hungría?

1.10. ¿Cómo describe sus recuerdos del viaje y el dolor por la muerte de sus padres en la guerra? ¿Podemos concluir que se muestra indiferente ante la guerra?

1.11. Interpretamos la escena donde Marwan y su padre se limpian los zapatos en pleno camino.

1.12. Asociamos los problemas políticos en la UE con los 12.000 refugiados que llegan a Eslovenia.

1.13. ¿Qué vínculos mantiene Jiham con sus padres?, ¿cómo afectan a su situación? Comentamos los planos en los que un anciano da vueltas en el aire a un niño pequeño.

1.14. Consideramos las diferentes versiones sobre las responsabilidades de cada país en la guerra. 


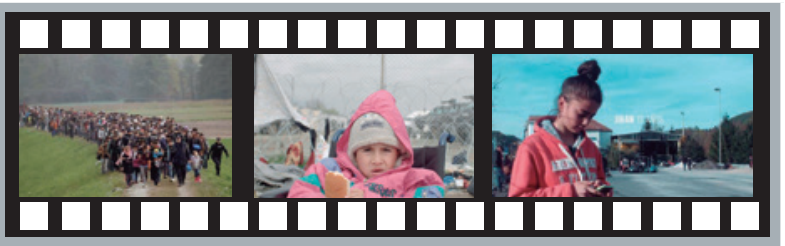

2.1. Enero 2016. Kilis, frontera entre Siria y Turquía. Kais, de 10 años, acompañado por su tío, es curado de sus heridas y habla de las circunstancias de su accidente (00:41:01).

2.2. Charla de Ángela Merkel (00:41:22).

2.3. Febrero 2016. Aachen, Alemania. Hamude describe su vida cotidiana en Alemania junto a su tío (00:44:39).

2.4. Discurso de Donald Tusk, presidente del Consejo Europeo (00:44:42).

2.5. Abril 2016. Campo de refugiados de Idomeni, Grecia, frontera con Macedonia. La vida cotidiana en el campo de refugiados: Mohamed, su padre y su hermano tratan de adaptarse al devenir de los días, añorando a la madre que salió primero y los espera en Alemania (00:48:26).

2.6. Marzo 2016. Berlín, Alemania. Jihan y su padre pasean por la ciudad y la niña cuenta las dificultades previas hasta llegar ahí. Se entrevistan con una abogada para arreglar su situación administrativa y obtener la reagrupación familiar (00:51:56).

2.7. Abril 2016. Campo de refugiados de Hotton, Bélgica. Marwan habla de su vida escolar, sus problemas con el francés. Le atormentan los malos sueños de la guerra. Hace nuevos amigos: Josaif de Egipto y Ahmad de Palestina (00:56:00).

2.8. Aachen, Alemania. Hamude expone sus cuestiones de integración: falta de amigos, dificultades con el alemán, añoranza de la familia, de los padres muertos, del hermano, de la tierra natal (00:57:30).

2.9. Imágenes de ciudades sirias destruidas (00:57:37).

2.10. Kilis, frontera entre Siria yTurquía. Kais está en casa de su tío, y en la comida vemos sus dificultades para comer y beber. El tío relata las graves secuelas psicológicas de la guerra en el niño (01:00:00).

2.11. Mayo 2016. Berlín, Alemania. Jihan usa constantemente el móvil para poder comunicarse con su madre. Pese a todo, siente que puede ir acostumbrándose a su nueva vida (01:03:00).

2.12. Campo de refugiados de Idomeni, Grecia. El padre y los hermanos de Mohamed hablan con la madre a través del móvil. El padre, enfermo a causa de las fiebres de Malta, recibe el tratamiento adecuado en el campo de refugiados (01:05:00).

2.13. Junio 2016. Mejora la vida para Marwan y su familia ya que finalmente obtienen los ansiados "papeles" (01:08:00).

2.14. Noticias de Euronews: las autoridades griegas comienzan a desalojar el campamento de Idomeni (01:09:00).
2.1. Reflexiona sobre el discurso infantil acerca de las culpas de esa guerra.

2.2. ¿Cuáles crees que deben ser las responsabilidades políticas de la acogida?

2.3. Pensamos en el transcurso de su vida escolar, sus juegos y añoranzas. Analizamos la secuencia en la que el niño juega con la bicicleta.

2.4. Compara su contenido con el pronunciado por Ángela Merkel

2.5. ¿Qué significan los planos picados de las tiendas de campaña y las ropas tendidas, también, los que recogen las pancartas y carteles por el campo? ¿Y el poema que Mohamed dedica a Siria, a su emotividad?

Comenta los planos detalle de los dibujos del niño evocando el recuerdo de la guerra.

2.6. Indaga sobre el problema de "los papeles" y las trabas administrativas que el país de acogida impone a los inmigrantes; y sobre la importancia de la reagrupación familiar. ¿Los Estados de la UE cumplen sus obligaciones para con los refugiados?

2.7. ¿Es posible normalizar la vida de los niños en un campo de refugiados?

2.8. Comparamos la experiencia de Hamude con la de Marwan.

2.9. Observa como esta secuencia enlaza en forma de simetría visual con el recuerdo de Hamude y las secuelas de la guerra en Kais.

2.10. Nos fijamos en el contraste que produce contemplar esas graves secuelas físicas en el niño con las imágenes de su juego con los amigos.

Observamos como Kais intenta atrapar una bolsa de plástico que lleva el viento: ¿cómo filmar la belleza y tratar de captar la fantasía infantil en plena barbarie? Reinterpretamos el mito de la infancia feliz como espacio utópico relacionado con la felicidad plena.

2.11. Valoramos la ligera evolución en la vida de Jihan: sale con sus amigas, se divierte, practica el Kick boxing para descargar tensiones. ¿Qué piensa sobre los derechos de las mujeres en Alemania y en Siria? ¿Cómo actúan las nuevas tecnologías en las relaciones familiares a distancia y en la dimensión afectiva de ese vivir trasnacional?

2.12. ¿Con qué dificultades se enfrentan muchos de esos refugiados para recibir atención sanitaria?

2.13. ¿Intuimos un final feliz para ellos? Adjetivamos la mirada de Marwan hacia el mar y meditamos sus palabras: "Estoy feliz por ver el mar sin pateras".

\subsection{Presta atención al desarrollo de este desalojo.}


2.15. Campo de refugiados de Idomeni, Grecia, Frontera con Macedonia. Mohamed relata la salida del campo de refugiados con su padre y su hermano y su llegada a Atenas. Visita infructuosa a la Embajada de Alemania. Imposibilidad de reunirse con la madre que está en Stuttgart (01:13:00).

2.16. Julio 2016. Hamude, Aachen, Alemania. Hamude y su tío se reencuentran con sus hermanos. Alegría de los niños que juegan juntos (01:16:00).

2.17. Berlín, Alemania. Jihan sigue conectada a su madre a través de móvil. (01:19:00)

2.18. Bruselas, Bélgica. Siguen las dificultades para conseguir un alquiler, pues la familia de Marwan carece de avales y sólo podrán permanecer en el campo de refugiados dos meses más (01:20:00)

2.19. El estado final de los protagonistas (01:22:00). Inserción final de significante cartográfico que nos ayuda a visualizar todo ese recorrido físico que han hecho los protagonistas.
2.15. ¿Cómo es el sufrimiento, de esa familia rota, completamente perdida en la gran ciudad? Valora la emotividad de la escena en la que Ripha, la madre, habla por vídeo conferencia con su familia.

2.16. Pensad en esta frase de un político: "Las fronteras son lo peor que han inventado los políticos". Asociamos esta secuencia con la de la familia de Mohamed al comunicarse en la distancia con la madre ausente.

2.17. Asistimos al desgarro que les produce la separación.

\subsection{Ante ello, ¿creéis que ha merecido la pena tanto esfuerzo?}

2.19. ¿Qué balance final podemos hacer de todas estas historias?

\section{Alęunas curiosidades de interês}

1. Sobre el director: Hernán Zin, nacido en Buenos Aires, en 1971, es un reportero de guerra, escritor y director de documentales italo-argentino. Es licenciado en Relaciones Internacionales, y desde hace 20 años recorre el mundo para realizar documentales, escribir reportajes y libros. Centra su labor en situaciones de pobreza extrema y en conflictos armados. Ha trabajado en más de 50 países de África, América Latina y Asia, viviendo durante tres años en Calcuta. Desde 1998 reside en Madrid a raíz del documental Vida y muerte en la estación de Calcuta, que rodó en 1997 junto al músico Nacho Cano.

2. Adquirió gran repercusión con su reconocido documental Nacido en Gaza, filmado entre Julio y Noviembre de 2014, en el que siguió las vicisitudes de 10 niños y niñas afectados por la operación israelí "Margen Protector". Con Nacido en Siria (2016) continúa en la misma línea de trabajo y compromiso.

3. Zin comenta que estaba rodando un documental sobre la caza de elefantes en África cuando vio en la televisión las imágenes de Aylan, el niño sirio ahogado en la playa turca. Al día siguiente ya estaba en Hungría, con la cámara en mano. Al principio eran veinte historias, pero luego quedaron reducidas a siete, porque a algunos de los niños los fueron perdiendo por el camino.

4. Además, señalamos otros trabajos suyos como: Villas Miseria (2009), La guerra contra las mujeres (2013), Quiero ser Messi (2013) y Diez elefantes (2015).

\section{Actividades de experiencia, reflekión y acciôn en común}

1. ¿Qué testimonios infantiles nos han impactado más?

2. Seleccionamos y debatimos las escenas más significativas. ¿Montaje alterno o paralelo para desarrollar la historia?

3. Comentamos estas declaraciones de Hernán Zin, director del documental:

"Según los datos de la Organización Internacional para las Migraciones (OIM), un $30 \%$ de los refugiados son niños. Aparte de seguir a los niños, yo quería hacer un reflejo de lo que ha sido la ruta, que fuese también un documento histórico. Mostrar no sólo el éxodo, sino también las trabas burocráticas, la no reunificación familiar, los problemas que se encuentran para integrarse (aprender el idioma, conseguir un trabajo, alquilar un piso) una vez llegan -los que llegan- al país de acogida". https://www.elconfidencial.com/cultura/2016-12-23/nacido-en-siria-documental-refugiados_1307558/

4. El director confiesa en esta entrevista datos personales sobre su trabajo, los cuales suscitan una intensa actividad de reflexión: su vínculo paternal con los niños, su obligación moral de mirarles a los ojos, la dureza de filmar el rostro desfigurado de Kais. Confiesa también que este filme le ha afectado mucho y que por eso planea darse un respiro con el cine de ficción, no sin antes hacer un documental Morir para contar sobre reporteros de guerra con estrés postraumático. http://www.eldiario.es/andalucia/lacajanegra/ seff2016/Hernan-Zin_0_577092615.html

5. ¿Por qué es importante que se vea esta película en Europa?

6. Resaltamos la situación traumática que sufren estos niños refugiados: muchos han perdido a sus padres y el éxodo comienza con el adulto que ha sobrevivido de la familia.

7. Buscamos películas que traten sobre la situación de la infancia en zonas de conflicto.

8. Ampliamos información sobre la campaña que la organización Save the children ha organizado en torno a la muerte en la playa del niño sirio, Aylan: ¿una imagen vale más que mil palabras? 